\title{
TIME DOMAIN MEASURES OF HEART RATE VARIABILITY TO ASSESS CARDIAC AUTONOMIC NERVE FUNCTION IN FEMALE WITH IRON DEFICIENCY ANEMIA
}

\author{
FARHANA RAHMAN ${ }^{1}$, QAZI SHAMIMA AKHTER ${ }^{2}$, QAZI FARZANA AKHTER ${ }^{3}$, SUSMITA SINHA ${ }^{4}$, SYBILA FERDOUSI ${ }^{5}$ \\ ${ }^{1}$ Assistant Professor, Department of Physiology, Delta Medical College, Dhaka \\ ${ }^{2}$ Professor and Head, Department of Physiology, Dhaka Medical College, Dhaka \\ ${ }^{3}$ Assistant Professor, Department of Physiology, Uttara Adhunik Medical College, Dhaka \\ ${ }^{4}$ Assistant Professor, Department of Physiology, Nightingale Medical College, Ashulia, Dhaka \\ ${ }^{5}$ Assistant Professor, Department of Physiology, University Dental College, Dhaka
}

\begin{abstract}
Iron deficiency anemia is considered as one of the major public health problem in Bangladesh. Cardiac autonomic nerve dysfunction may present in iron deficiency anemia which increases the risk and further complications of this disease. Assessment of heart rate variability (HRV) is a non-invasive technique to evaluate cardiac autonomic nerve function status. To assess the cardiac autonomic nerve function status by heart rate variability analysis in female with iron deficiency anemia. This cross sectional study was conducted in the Department of Physiology, Dhaka Medical College, Dhaka from July 2012 to June 2013. For this, 100 female subjects with iron deficiency anemia aged 20-45 years were included in the study group (Group B). The anemic subjects were selected from Outpatient Department of Haematology in Bangabandhu Sheikh Mujib Medical University (BSMMU), Dhaka. They were included in the study group on the basis of their pre-performed hemoglobin percentage, total count of RBC and serum ferritin level. Data were collected in pre-designed structured questionnaire by the researcher herself. For comparison, age and sex matched 100 apparently healthy female were selected as control (Group A) by personal contact from the different areas of Dhaka city. Analysis of HRV parameters were done in Department of Physiology, Bangabandhu Sheikh Mujib Medical University (BSMMU), Dhaka. The HRV parameters were recorded by a 4 active channels, Polyrite-D.For statistical analyses, unpaired Student's t-test and Pearson's correlation coefficient test were performed by using SPSS (version-19) as applicable. Mean resting pulse rate and mean heart rate were significantly $(p<0.0001)$ higher in subjects with iron deficiency anemia in comparison to those of control group. Hemoglobin concentration, total count of RBC, mean $R-R$ interval, SDNN and RMSSD were significantly ( $p<0.0001)$ lower in subjects with iron deficiency anemia in comparison to those of healthy control. This study concludes that cardiac parasympathetic activity was reduced in female with iron deficiency anemia.
\end{abstract}

Keywords: Heart rate variability, Iron deficiency anemia.

(Bangladesh J Physiol Pharmacol 2014;30(1):1-5.)

\section{INTRODUCTION}

Anemia may be defined as decreased concentration of hemoglobin level in the blood below the lower limit of the normal range in respect of age and sex of the individual. ${ }^{1}$ It is the most common disorder of the blood. Here the number of red blood cell is decreased and consequently their oxygen-carrying capacity is insufficient to meet the body's physiological needs. Anemia is a global public health problem affecting both developing and developed countries with major consequences for human health, social and

Address for correspondence: Farhana Rahman, Assistant Professor, Department of Physiology, Delta Medical College, Dhaka. economic development. Globally anemia affects 1.62 billion people which correspond to $24.8 \%$ of the population. ${ }^{2}$ The prevalence of anemia among adult non pregnant females in Bangladesh is $45 \%$. The causes of anemia in a population are multiple. Iron deficiency is the most important cause of nutritional anemia worldwide. ${ }^{3}$

There are more than 400 types of anemia, which are divided into three groups. Anemia caused by blood loss such as gastric ulcers, CA-rectum, hook worm infestation, menorrhagia etc. Anemia caused by decreased or faulty red blood cell production such as iron deficiency, vitamin $B_{12}$ deficiency, sickle cell anemia, bone marrow and stem cell disorder, leukemia 
etc. Anemia caused by destruction of red blood cells such as thalassemia, sickle cell anemia, other hemolytic anemia. $^{4}$

Causes of iron deficiency anemia in female of 2045 years include- lack of iron in diet, blood loss due to any etiology, inability to iron absorb and pregnancy. ${ }^{5}$

Anaemia is an independent risk factor for adverse cardiovascular outcomes in the general population. ${ }^{6}$ It was previously reported that heart rate variability was decreased in anemic patients. ${ }^{7,8,9}$ And the low heart rate variability can potentially increase the cardiac risk. ${ }^{8}$

Autonomic nervous system (ANS) plays an important role in the regulation of the physiological processes of the human during normal and pathological conditions. Among the techniques used in its evaluation, the heart rate variability (HRV) has been a simple and non-invasive measure of the autonomic impulses. It represents one of the most promising quantitative markers of the autonomic balance. The HRV describes the oscillations in the interval between consecutive heart beats (RR interval), as well as the oscillations between consecutive instantaneous heart rates. It is a measure that can be used to assess the ANS modulation under physiological conditions, such as wakefulness and sleep conditions, different body positions and physical training. HRV also assess the ANS changes during any pathological conditions. Changes in the HRV patterns provide a sensible and advanced indicator of health involvements. ${ }^{10}$

Heart rate is influenced by sympathetic and parasympathetic nervous systems, reflexes and respiration. HRV enables clinicians and researchers to examine the influences of autonomic activity on heart rate. $^{11}$

HRV reflects autonomic nervous control. Normally heart rate variation is related to the balance between sympathetic \& parasympathetic nervous system which provides early better qualitative and quantitative interpretation of sympathovagal modulation and can detect autonomic impairment. High HRV reflects good adaptability and well-functioning autonomic control. On the other hand, reduced heart rate variability acts as a strong predictor of risk for adverse events in patients with wide range of diseases. ${ }^{12}$

HRV assesses the difference of the periods between consecutive heart beats. These differences of the periods vary under autonomic control. Decreased HRV has been recognized as a strong indicator of risk in healthy as well as diseased individuals.

The relationship between anemia and heart rate variability have been searched in several types of anemia like thalassaemia ${ }^{13}$ Vitamin $B_{12}$ deficiency and megaloblastic anemia, ${ }^{14}$ sickle cell trait. ${ }^{15}$ However, there are insufficient data about autonomic functions in patients with iron deficiency anemia, the leading cause for anemia in the general population. ${ }^{16}$

Yokusoglu et al. ${ }^{17}$ reported impairment in HRV indices due to increased sympathetic or decreased parasympathetic activity in iron deficiency anemia. It is reported that supplementation of iron is effective in improving the dysregulation of autonomic nervous system reflexes. ${ }^{18}$

It was reported that HRV parameters were decreased in patients with vitamin $B_{12}$ deficiency. But the decrease in sympathetic HRV parameters was greater than those measured in parasympathetic HRV parameters. ${ }^{14}$

On contrary some investigators observed there was no significant difference between the healthy group and iron deficient anemic patients in regard to HRV parameters. ${ }^{16,19}$

The exact relationship between HRV parameters and anemia remains elusive. So far it is known that the changes in HRV parameters as a result of iron deficiency anemia by both microcomputer based time and frequency domain method or conventional method has not yet been done in our country. Again, we need to know the value of HRV parameters in female subjects with iron deficiency anemia of Bangladesh for our own standard baseline as well as for reference value. Therefore, this study has been designed to assess the cardiac autonomic nerve function by analyzing the HRV parameters in adult female subjects with iron deficiency anemia.

\section{MATERIALS AND METHODS}

This cross sectional study was conducted in the Department of Physiology, Dhaka Medical College, Dhaka from July 2012 to June 2013. For this, 100 female subjects with iron deficiency anemia aged 20-45 years were included in the study group (Group B). The anemic subjects were selected from Outpatient Department of Haematology in Bangabandhu Sheikh Mujib Medical University (BSMMU), Dhaka. They were included in the study group on the basis of their preperformed hemoglobin percentage, total count of RBC and serum ferritin level. Data were collected in predesigned structured questionnaire by the researcher herself. For comparison, age and sex matched 100 apparently healthy female were selected as control (Group A) by personal contact from the different areas of Dhaka city. All the subjects were free from hypertension, cardiovascular disease, any endocrine disorder, renal disease, psychic disorder and any hereditary disease. Subjects with pregnancy and habit of smoking were excluded.

The subjects were thoroughly informed about detail procedure of the study and informed written consent was taken. The subjects were advised to have their meal by 9:00 pm night before the examination 
and have to remain free from any physical or mental stress. They cannot take any sedatives or drugs affecting central nervous system. The subjects were also asked to have light breakfast and avoid tea or coffee at breakfast. On the day of examination, the subjects were advised to attend the Autonomic NerveFunction Test Laboratory in the Department of Physiology of Bangabandhu Sheikh Mujib Medical University, Dhaka between 9 am to $1 \mathrm{pm}$ on the day of examination. Whenever the subject appeared in the department, then the subject was interviewed and detail history regarding personal history, drug history, past medical history were taken. Then thorough physical examinations and anthropometric measurement including height, weight and BMI were taken. Then the subject was prepared to perform Autonomic Nerve Function Test. She was kept in complete bed rest in supine position for 15-20 minutes in a cool and calm environment. During this period subject was advised not to talk, eat or drink and also not to perform any physical or mental activity, even sleep. Then all preparations for recording of the HRV parameters were made by connecting the channels of ECG. A five minutes recording of the time domain HRV parameters such as mean R-R interval, mean heart rate, SDNN, RMSSD were recorded by a 4 active channels, Polyrite-D. For statistical analyses, unpaired Student's t-test and Pearson's correlation coefficient test were performed by using SPSS (version-19) as applicable.

\section{RESULTS}

Both the groups were matched for age and BMI.

Mean value of mean heart rate was significantly higher and mean R-R interval was significantly $(p<0.05)$ lower in group $B$ than that of group A.(Table I)

The mean values of SDNN and RMSSD were significantly $(p<0.05)$ lower in group $B$ than that of group A. (Table I)

Table I: Simple and Statistical time domain parameters in both groups $(n=200)$

\begin{tabular}{cccc}
\hline Parameters & $\begin{array}{c}\text { Group A } \\
\mathbf{n = 1 0 0}\end{array}$ & $\begin{array}{c}\text { Group B } \\
\mathbf{n = 1 0 0}\end{array}$ & $\begin{array}{c}\mathbf{p} \\
\text { value } \\
\text { Group } \\
\text { AvsB }\end{array}$ \\
\hline $\begin{array}{c}\text { Mean R-R } \\
\text { (sec) }\end{array}$ & $\begin{array}{c}0.80 \pm 0.07 \\
(0.63-1.06)\end{array}$ & $\begin{array}{c}0.70 \pm 0.09 \\
(0.49-0.997)\end{array}$ & 0.0001 \\
$\begin{array}{c}\text { Mean HR } \\
\text { (beats/min) }\end{array}$ & $\begin{array}{c}75.3 \pm 6.84 \\
(57-96)\end{array}$ & $\begin{array}{c}86.73 \pm 11.64 \\
(60-123)\end{array}$ & 0.0001 \\
SDNN & $73.5 \pm 18.65$ & $46.93 \pm 26.60$ & 0.0001 \\
(ms) & $(39.56-142.3)$ & $(20.28-185.42)$ & \\
RMSSD & $89.77 \pm 25.67$ & $56.64 \pm 35.06$ & 0.0001 \\
(ms) & $(42.56-167.98)$ & $(25.68-261.64)$ & \\
\hline
\end{tabular}

Results are expressed as Mean \pm SD. Figures in parenthesis indicate ranges.
Unpaired Student's ' $\mathrm{t}$ ' test was performed to compare between groups. The test of significance was calculated and $p$ values $<0.05$ was accepted as level of significance.

$\mathrm{n}=$ Number of subjects

Group A: Healthy subjects (control)

Group B: Subjects with iron deficiency anemia

Mean $\mathrm{HR}=$ Mean heart rate

Mean RR $=$ Mean R-R interval

SDNN = Standard deviation of NN interval

RMSSD = Square root of mean squared differences between adjacent NN intervals

\section{DISCUSSION}

In the present study, findings of HRV parameters in healthy control group were almost within normal range and also similar to those reported by the various investigators from different countries ${ }^{9,14,17,20-22}$ and also from our country. ${ }^{23-25}$

In this study, the mean values of R-R interval was significantly lower in anemic subjects when compared with that of controls. Similar type findings were also reported. There was significantly higher in the mean values of heart rate in subjects with iron deficiency anemia. ${ }^{26}$ This finding is in consistent with the findings of some other investigators of other countries $16,17,20$

$l_{1}$ the present study, the mean SDNN and RMSSD in subjects with iron deficiency anemia were significantly lower than that of controls. Similar type of finding was also observed by various researchers. ${ }^{17}$ Moreover, Tuncer et al. ${ }^{16}$ Lutfi et al. ${ }^{20}$ reported that there was no significant difference of mean SDNN and RMSSD in anemic subjects in comparison to that of healthy control.

There are some postulated mechanisms suggested by various researchers of different countries which may imply the possible mechanism regarding the involvement of autonomic nerve function activity in anemic patients.

It has been suggested that parasympathetic activity decreases and sympathetic activity increases in patients with iron deficiency anemia. The imbalance between sympathetic and parasympathetic nerve activities can change the electrophysiologic activity of the heart. ${ }^{17}$

In iron deficiency anemia, there is reduced $\mathrm{O}_{2}$ carrying capacity of blood due to decreased hemoglobin concentration. Thus hypoxia occurs. This hypoxia is sensed through carotid bodies and increases sympathetic activity. ${ }^{27}$ 
The anemic hypoxia stimulates adrenergic nervous system. Stimulated adrenergic nervous system is responsible for cardiovascular response i.e. tachycardia and increased cardiac output. These cardiovascular changes try to compensate the decrease in blood oxygen content. In hypoxia the activation of adrenergic system is observed by elevated plasma and urine norepinephrine concentration. ${ }^{28}$

Again, subjects with anemia have low basal parasympathetic outflow to increase the heart rate as compensatory mechanism. ${ }^{29}$

In the present study, time domain HRV analysis showed reduced vagal tone is indicated by lower values of SDNN and RMSSD in patients with iron deficiency anemia. But in this study, the anemic hypoxia was not assessed by blood gas analysis and increase in adrenergic activity was not assessed by measuring serum and urinary catecholamine levels. Therefore, the exact mechanisms involved for decreasing cardiac parasympathetic activity in subjects with iron deficiency anemia cannot be elucidated from this study. However to explore the pathophysiological basis of this reduced parasympathetic activity in iron deficiency anemia, further in depth studies are required involving both anemic subjects and appropriate animal model.

\section{CONCLUSION}

This study concludes that cardiac parasympathetic is reduced in female subjects with iron deficiency anemia.

\section{REFERENCES}

1. Firkin F, Chesterman C, Penington D, \& Rush B.de Gruchy's Clinical Haematology in Medical Practice, $5^{\text {th }}$ ed. Thompson Press (India) Ltd, India; 1989.

2. WHO Global Database on Anemia 2008, Worldwide prevalence of anemia 1993-2005, viewed 17 Nov 2012, available from, http://whqlibdoc.who.int/publications/2008/9789241596657_en g.pdf

3. Ahmed F. Anaemia in Bangladesh: a review of prevalence and aetiology.Pub Health Nutr. 2000; 3: 385-393.

4. Klodas E 2012, 'Understanding Anemia -basics', viewed 11 April 2013, available from, http://www.webmd.com/a-to-z-guides/ understanding-anemia-basics.

5. Kaushansky K, Lichtman MA, Butler E, Kipps TJ, Seligsohn U, \& Prchal JT. Williams Hematology. 8th edn, The McGraw-Hill Companies, China.

6. Sarnak MJ , Tighiouart H , Manjunath G, MacLeod B, Griffith J , Salem D, \& Levey AS. Anaemia as a risk factor for cardiovascular disease in the Atherosclerosis Risk in Communities (ARIC) study. J Am CollCardiol. 2002; 108: 21542169.

7. Navruz O, Yokosuglo M, Uzun M, Demirkol S, Avcu F, Baysan O, Koz C, Cetin T, Sag C, Ural AU, \&Isik E. Cardiac autonomic functions are altered in patients with acute leukemia, assessed by heart rate variability. Tohoku J Exp Med. 2007; 211: 121126.
8. Gehi A, Ixj, Shilpak M, Pipkin SS, \& Whooley MA. Relation of anaemia to low heart rate variability in patients with coronary heart disease (from heart and soul study). Am J Cardiol. 2005; 95: 1474-1477.

9. Sozen $A B$, Demirel $S$, Akkaya $V$, Kudat $H$, Tukek $T$, Yeneral $M$, Ozcan M, Guven O, \& Korkut F. Autonomic dysfunction in vitamin $B_{12}$ deficiency: a heart rate variability study. J Auton Nerv Syst. 1998; 71:25-27.

10. Vanderlei LC, Pastre CM, Hoshi RA, Carvalho TD, \& Godoy MF. Basic notions of heart rate variability and its applicability. Rev Bras Cir Cardiovasc.2009; 24: 205-217.

11. Jong MJD \& Randall DC. Heart rate variability analysis in the assessment of autonomic function in heart failure. J Cardiol Nursing. 2005; 20:186-195.

12. Everengul $H$, Dursunoglu D, Cobankara V, Polat B, Seleci D, Kabukeu S, Kaftan A, Semiz E, \& Kilic M. Heart Rate Variability in Patients with Rheumatoid Arthritis. Rheumatol Int. 2004; 24: 198-202.

13. De Chiara B, Crivellaro W, Sara R, Ruffini L, Parolini M, Fesslova V, Vittorio C, Cesare F, \& Oberdan P. Early detection of cardiac dysfunction in thalassaemic patients by radionuclide angiography and heart rate analysis. Eur J Haematol, 2005; 74: 517-522.

14. Ayetmir K, Aksoyek S, Buyukasik Y, Haznedaroglu I, Atalar E, \& Ozer N. Assessment of autonomic nervous system functions in patients with vitamin $\mathrm{B}_{12}$ deficiency by power spectral analysis of heart rate variability. Pacing Clin Electrophysol. 2000; 23: 975-978.

15. Connes P, Martin C, Barthelemy JC, Monchanin G, Atchou G, Forsuh A, Massarelli $R$, Wouassi $D$, Thiriet $P$, \&Pichot V. Nocturnal autonomic nervous system activity impairment in sickle cell trait carriers. Clin Physiol Funct Imaging. 2006; 26: 87-91.

16. Tuncer $M$, Gunes $Y$, Guntekin $U$, Gumrukcuoglu HA, Eryonucu B, Guler N, Dilek I, \& Demir C. Heart rate variability in patients with iron deficiency anemia. Arq Bras Cardiol. 2009; 92: 368371.

17. Yokusoglu M, Nervuz O, Baysan O, Uzun M, Demirkol S, Avcu F, Koz C, Cetin T, Hasimi A, Ural AU, \& IsikE. Tohoku J Exp Med.2007; 212: 397-402.

18. Orii $K E$, Kato $Z$, Osamu $F$, Funato $M$, Kubodera $U$, Inoue $R$, Shimozawa N, \& Kondo N. Changes of autonomic nervous system function in patients with breath- holding spells treated with iron. J Child Neurol. 2002; 17: 337-340.

19. Shetty KP, Moodithaya S, Naik A, \&Mirajkar A. Autonomic nervous system activity among adolescent girls with iron deficiency anemia. Nat J Bas Med Sci. 2012; 2: 224-229.

20. Lutfi MF. Effects of Hemoglobin Concentration on Heart Rate Variability. Int J Pharmacol Biol Res. 2011; 2: 127-131.

21. Kardelen F, Tezean G, Akeurin G, Ertug H, \& Yesilipek A. Heart rate variability in patients with Thalassemia Major. Pediatr Cardiol. 2008; 29: 935-939.

22. Shukla J, Gupta R.C, Singh J, \& Shukla A.K. Heart Rate Variability Analysis in Patients with Beta Thalassemia Major. Int J Bas App Chem Sci. 2012; 2: 10-13.

23. Mithun S. Comparative Study of Cardiac Autonomic Nerve Function Status by Heart Rate Variability between Sedentary and Heavy Workers. 2009; MPhil Thesis, BSMMU. 
24. Nayem M. Characterization of autonomic nerve functions in patients with Irritable Bowel Syndrome. 2011; MPhil Thesis, BSMMU.

25. Jahan K. Assessment of cardiac autonomic nerve function status in patients with Rheumatoid Arthritis. 2011; MPhil Thesis BSMMU.

26. Franzoni F, Galetta F, Muro CD, Buti G, Penntimone F, \& Santoro $G$. Heart rate variability and ventricular late potentials in $\beta$ - thalassemia major. Heamatologica. 2004; 89: 233-234.

27. Schultz HD, \& Sun SY. Chemoreflex function in heart failure. Heart Fail Rev. 2000; 5: 45-46.

28. FavretF, \& Richalet JP. Exercise and hypoxia: The role of the autonomic nervous system. RespPhysiolNeurobiol.2007; 158: 280-286.

29. Lakhotia M, Shah PK, Gupta A, Jain SS, Aggarwal M, \& Dadhich S. Clinical assessment of autonomic functions in anemic. J Assoc Physicians India. 1996; 44: 534-536. 